\title{
Characteristics of Effective Dynamics and its Use in Developing the Product Quality and Proceeds in Inclusively Firm
}

\author{
Nasir Al Kloub \\ Mechanical Engineering Department, Faculty of Technological Engineering \\ Al Balq's Applied University, Jordan Al Salt P.O. Box 861, Jordan
}

\begin{abstract}
Controlling product size type and quality is a set of technical, technological, organizational and preparatory procedures correlated in one process. Indexes for the demand for product in foreign and local markets vary according to its quality, and consequently technological processes should guarantee and warrant protects of subtle qualities and quality indexes. Securing quality of the product in all industrial sectors depend on large extent on machines building industry and technical and technological advancement. Engineering economies helps a lot in upgrading product quality and standards through studying the potentials of industrial establishment, equipping and period maintenance methods thereof. Thus, the aim from controlling quality standard through studies, researches and prototypes is to form and create optimal standard for the new products based on technical and technological advancement achievements. In this research the dynamic index was used as it is designed for reflecting the success and efficiency of the material and scientific potentials and the technical and technological policy oriented to industry and upgrading the standard, level and quality of the product and finds technical solutions and evaluates performance of the industrial firm.
\end{abstract}

Key words: Effective dynamics, developing, product

\section{INTRODUCION}

In general, production efficiency is described by a number of technical and economic outcome and by evaluation them economically.

Economic evaluation of production fundamentals (capital, expansion in production, development of work force, volume and quality of industrialization in ordinary circumstances, economic relation of quality, competitive capability of products in the domestic and foreign markets, modernizing industrial machines in firms and introducing modern technology into factories) should be studied and activated to ensure product endurance and qualities in the market in a successful and reliable manner ${ }^{[1,2]}$.

It seems more rational to find one general and designed index that could reflect all economic activity aspects of the industrial firm and its productive departments.

We suggest to use the dynamic index due to the importance attached now to industrializations. This indicator is designed to reflect the success and efficiency of the use of material and practical capabilities directed to industry. This index reflects also success of the technical policy oriented towards upgrading the level and standards of finished product and finding the used and applied technical solutions. In orders to evaluate productive efficiency, the general proposed dynamic index allow topically to evaluate all aspects of firm's activity and work not at the present moment only but doss during the following period .

We insert the following symbols:

$B_{i}(t)=$ Product volume from its first model in $(t), i=$ $1, \ldots, \mathrm{n}(\mathrm{t})$

$n(t)=$ Product quantity in $(t)$

$P_{i}(t)=$ First product selling price in $(t)$ year

Calculated from the following relation

$P_{i}(t)= \begin{cases}0 & ; \mathrm{t}<\phi_{\mathrm{i}} \\ \mathrm{P}_{\mathrm{i}}\left(\phi_{\mathrm{i}}\right) \pm a_{i}^{1}\left(t-\phi_{\mathrm{i}}\right) & ; 1 \leq t-\phi_{\mathrm{i}} \leq t_{i} \\ \mathrm{P}_{\mathrm{i}}(\varnothing \mathrm{i}) \pm a_{i}^{1}\left(t-\phi_{\mathrm{i}}\right)-a_{i}^{2}\left(t-\phi_{\mathrm{i}}\right) ; t-\phi_{\mathrm{i}}<t \leq \lambda \\ \mathrm{P}_{\mathrm{i}}(\tau) & ; \mathrm{t}<\tau_{i}\end{cases}$

where

$\emptyset_{\mathrm{i}^{-}} \quad$ Manufacturing year for the first product.

$P_{i}\left(\emptyset_{i}\right)=$ Product price in the same year in which raw materials were purchased.

$\alpha^{1}{ }_{i}(t)=$ Price decrease or increase coefficient in case of increasing or decreasing production level.

$\alpha_{2}^{\mathrm{i}}(\mathrm{t})=$ Product selling price decrease coefficient after the stage of $\left(\mathrm{t}_{\mathrm{i}}-\phi_{\mathrm{i}}{ }^{2}\right)$ of the years in which the product is replaced with more advanced one.

$P_{i}(\tau)=$ Product selling price after expiry of planned life cycle.

Inserting dynamic indicator to product selling price prompt work groups to exert more efforts to modernize and develop the product and introduce new designs in the industry. 
$\rho P_{i}(t)$ value shall be inserted also, which is a conditional addition to the price of first product in case of experiment in order to find out requirements of local and foreign markets. Therefore:

$$
P_{i}(t)=\bar{P}_{i}(t)+\beta_{i}(t) \Delta P_{i}(t)
$$

Where

$\beta_{i}(t)=0$ or 1 , which is connected with the initial experimental results.

Lets suppose $C_{i}(t)$ are the manufacturing expenses related to the first product in the year $(\mathrm{t})$, which include the following components:

$\mathrm{C}_{1 \mathrm{i}}(\mathrm{t})=$ Raw materials price, semi-finished products, assembly units and supplied materials commission.

$\mathrm{C}_{2 \mathrm{i}}(\mathrm{t})=$ Labor wages along with compensations and deductions.

$\mathrm{C}_{3 \mathrm{i}}(\mathrm{t})=$ Electricity, water and heating consumption bills ...etc.

$\mathrm{C}_{4 \mathrm{i}}(\mathrm{t})=$ Machines and equipment repair expenses.

$\mathrm{C}_{5 \mathrm{i}}(\mathrm{t})=$ Consumable equipment renovation expenses.

$\mathrm{C}_{6 \mathrm{i}}(\mathrm{t})=$ Return technical supplies and develop technology for launching new products.

$\mathrm{C}_{7 \mathrm{i}}(\mathrm{t})=$ Research and design expenses for developing the product to keep pace with the time.

$\mathrm{C}_{8 \mathrm{i}}(\mathrm{t})=$ Consumable expenses department $\left(7_{\mathrm{i}}\right)$ related to finding a way for expanding the launching of product in its initial form in the market.

$\mathrm{C}_{8 \mathrm{i}}(\mathrm{t})=\mathrm{A}_{\mathrm{i}} / \tau_{\mathrm{i}}$

$\mathrm{A}_{\mathrm{i}}=\quad$ Total expenses on the design of first product (first prototype)

$\tau_{\mathrm{i}=} \quad$ Practical life phase product.

$\mathrm{C}_{9 \mathrm{i}}(\mathrm{t})=$ Expenses of guarantee and warranty of first product.

$\mathrm{C}_{10, \mathrm{i}}(\mathrm{t})=$ Expenses connected with delay fines in delivering product to consumer, losses involving inefficiency of product operation by consumer and advertisement expenses.

$\left.\mathrm{C}_{11, \mathrm{i}} \mathrm{t}\right)=$ Expenses chargeable to treasure in connection with covering continuous productions expenses.

$\mathrm{C}_{12, \mathrm{i}}(\mathrm{t})=$ Packing, packaging and transporting expenses.

$\left.\mathrm{C}_{13, \mathrm{i}} \mathrm{t}\right)=$ Value and depreciation of property related to initial production line.

Therefore, we reach the following equation:

$C_{i}(t)=\sum_{i=1}^{12} C_{1 i}(t)-C_{13 i}(t)$

When also reviewing other expenses related to industrial firm operations:

$\mathrm{E}_{1}(\mathrm{t})=$ Rental installments.

$\mathrm{E}_{2}(\mathrm{t})=$ Expenses for administrative staff and deductions of local and governmental funds.

$E_{3}(t)=$ Expenses for conducting future researches.

$\mathrm{E}_{4}(\mathrm{t})=$ Building expenses.

$\mathrm{E}_{5}(\mathrm{t})=$ Other expenses taking into consideration (fines, losses...etc).
$\mathrm{E}_{6}(\mathrm{t})=$ Expenses for improving living conditions and services provided to the firm's employee.

$E_{7}(t)=$ Actual expenses spent for building repair and rehabilitation.

We find that the grand total of expenses from the following equation is:

$E_{i}(t)=\sum_{\lambda=1}^{7} E_{\lambda}(t)-E_{1}(t)$

Dynamics indicator, which reflects medium value of profit, industrial firm profitability and production management during the years $\left(t_{1}, t_{2}\right)$ in the following relation:

$D_{n}\left(t_{1}, t_{2}\right)=\frac{1}{t_{1}+t_{2}} \sum_{t=t_{2}}^{t_{2}}\left[\sum_{i=1}^{n}\left(P_{i}(t)-\sum_{i=1}^{12} C_{i 1}(t)+C_{i 13}(t)\right) B_{i}-\sum_{\lambda=2}^{4} E_{\lambda}(t)+E_{1}(t)\right]$

In case of $\left(t_{2}=t_{1}\right)$ the indicator $D_{n}\left(t_{1}, t_{2}\right)$ reflects the profit transferred to the firm, generated during certain time period or time (e.g. one year). But it would be rational to view the return and profit as a medium indication during several years $\left(\mathrm{t}_{1}, \mathrm{t}_{2}\right)$.

The dynamic index gives tangible profits which reflect on the effectiveness and productivity of workforce and takes into consideration that product will not be delayed and that it is necessary to manage economically and to preserve materials and wealth and seek to increase product volume, improve its quality and develop and modernize it and motivate workers in general and in particular ${ }^{[1,3]}$. Technical and technological solutions shall be found permanently. Consequently, profit is a designed synthetic index, which in turn save effort, materials and wealth and leads to work progress and reflects the economic aspects and activities of the firm.

The proposed dynamic index for the proceeds and profits (5) unifies all indexes in one objective by creating links between them. Results of the basic productive activity during phase $\left(t_{1}, t_{2}\right)$ defines its technical, scientific and economic policy applied and develop technical economy of the firm and introduce scientific advancement achievements in industry.

Dynamic index of firms' profits does not take into consideration capital expenses for enhancing production effectiveness and work productivity as stipulated by industry support fund. These expenses could remarkably surpass the effectiveness resulting from work productivity and increasing manufacturing volume.

Undoubtedly, the dynamic index could observe firm operation and reflect the basic principle for the economic computation, manufacturing processes and productive funds balances capability.

Profitability index and industry proceeds are expressed as a percentage that shows the relation of profit to the annual average of basic production funds balances and value of the annual average current capital. 
In order to evaluate manufacturing proceeds of the firm in accordance with dynamic index it is necessary to define the actual value of basic funds balances taking the following into consideration:

a. Its decrease during the calculation period.

b. Increase of its value at the expense of its partial renewal during general reparations.

c. Expenses for rehabilitating basic financial funds balances decrease after depreciation.

Basic funds balances decrease each year in as much as the deducted installments. Consequently, the actual basic value in the year ( $t$ ) is calculated taking into consideration the deductions during the investment phase. The longer the investment period is the more will be the maintenance and repair expenses in order to maintain the technical and technological position and normal production. In this case, the source of expenses is production proceeds while the source of general repairs is depreciation expenses.

Actual value of basic production funds in the firm $(\mathrm{t})$ is determined as follows:

$F g(t)=\frac{F_{o c}^{1}(t)+F_{o c}^{2}(t)}{2}+\frac{F_{o 1}^{1}(t)+F_{o 1}^{2}(t)}{2}-\frac{I_{F}^{1}(t)+I_{F}^{2}(t)}{2}$

Noting that: $\mathrm{F}_{\text {oc }}^{1}(\mathrm{t}), \mathrm{F}^{2}{ }_{\text {oc }}(\mathrm{t}), \mathrm{F}^{1}{ }_{\mathrm{ol}}(\mathrm{t}), \mathrm{F}^{2}{ }_{\mathrm{ol}}(\mathrm{t})$ - Respectively, are values of basic funds balances at the beginning and end of the year.

While the value (t) $I_{F}^{1}(t), I_{F}^{2}(t)$ represent depreciated value and taken out of the basic fine balance during the year $(\mathrm{t})$ and investment.

$\Delta I_{F}(t)=I_{F}^{2}(t)-I_{F}^{1}(t)=E_{1}(t)+\sum_{i=1}^{n} C_{i 13}(t)-\left(E_{6}(t)+\sum_{i=1}^{4}\left(C_{4 i}(t)+C_{5 i}(t)+E_{F}(t)\right)\right)$

Therefore, the dynamic index of middle production profit during phase $\left(t_{1}, t_{2}\right)$ is determined according to the following equation:

$$
\begin{aligned}
& M_{n}\left(t_{1}, t_{2}\right)=\frac{1}{t_{2}-t_{1}} \sum_{t=t}^{t_{2}} \frac{D_{n}(t)}{F_{g}(t)}= \\
& \frac{1}{t_{2}-t_{1}} \sum_{i=t_{1}}^{2} \frac{\left.2 \sum_{i=1}^{n}\left(P_{i}(t)-\sum_{i=1}^{12} C_{1 i}(t)+C 13(t)\right) B_{i}-\sum_{\lambda=2}^{4} P_{\lambda}(t)+P_{1}(t)\right]}{F_{o c}^{1}(t)+F_{o c}^{2}(t)+F_{o 2}^{1}(t)+F_{o 1}^{2}(t)-I_{F}^{2}(t)+I_{F}^{1}(t)}
\end{aligned}
$$

Evaluation of the economic efficiency of the firm in accordance with its basic industrial activity by an important economic index, which is the effectiveness factor of funds balance determined according to the following equation:

$$
K_{e f}\left(t_{2}-t_{1}\right)=\frac{\bar{O}_{H}\left(t_{2}-t_{1}\right)}{F g\left(t_{2}-t_{1}\right)}
$$

$$
\begin{aligned}
& O_{H}\left(t_{2}-t_{1}\right)=\sum_{t=t_{1}}^{t_{2}}\left[\sum_{i=1}^{n}\left(\hat{P}_{i}(t)-\sum_{i=1}^{12} C 1 i(t)+C 13 i(t)\right)\right. \\
& \left.B_{i}(t)-\sum_{\lambda=2}^{4} E_{\lambda}(t)+E_{1}(t)\right] \\
& F_{g}\left(t_{2}-t_{1}\right)=\frac{1}{t_{2}-t_{1}} \sum_{t=t_{1}}^{t_{2}} F_{g}(t)
\end{aligned}
$$$$
\mathrm{O}_{\mathrm{H}}\left(\mathrm{t}_{2}-\mathrm{t}_{1}\right) \text { Amount of collection during the period }
$$

From the relation $(10.4) \mathrm{P}_{\mathrm{i}}(\mathrm{t})$, being the actual retail price of selling a product of its first type during the ( $\mathrm{t}$ ) year. Its production proceeds and production profit can be expressed through significant economic indexes such as amount of funds, expenses for work team, share of each individual from the balances of production funds, expenses for producing limited quantity of goods, goods distribution factor, and its return compared with production funds balances.

\section{CONCLUSION}

By studying and activating engineering economics in the industrial firm and production we can reach the optimal solution to handle technical and technological matters through the economic index of industrial firm, which in turn conceal all economic effectiveness sources to increase export volume and update products.

The most important characteristics of the dynamic index is that it permits completion of collection of all factors affecting economic indexes of firm's activity, whether in increasing production and upgrading product quality or integration of practical, experimental and technological designs and studies, it reflects economic effectiveness success of restructuring process and qualifying the industry technically.

This is in addition to adding new profits to the balances, minimizing sizes of insurance reserves and speed of funds turnover in production funds balances.

\section{REFERENCES}

1. Azagladof, G.G., 1982. Theoretical and practical evaluation of the products quality. M: Economic, pp: 182.

2. Alfaiorva, Z.V., 1993. The Theory of Algorithms. M. Statistics, pp: 164.

3. Hitomi, K., 1985. Manufacturing system Engineering. Taylor and Fracis Ltd. London, pp: 310 . 